$$
\operatorname{CONF}-950412--37
$$

\title{
Molecular Dynamics Simulation of Mechanical Deformation of Ultra-Thin Amorphous Carbon Films
}

\author{
J.N. Glosli \\ M.R. Philpott \\ J. Belak
}

This paper was prepared for submittal to the

Materials Research Society

San Francisco, CA

April 21, 1995

April 1995

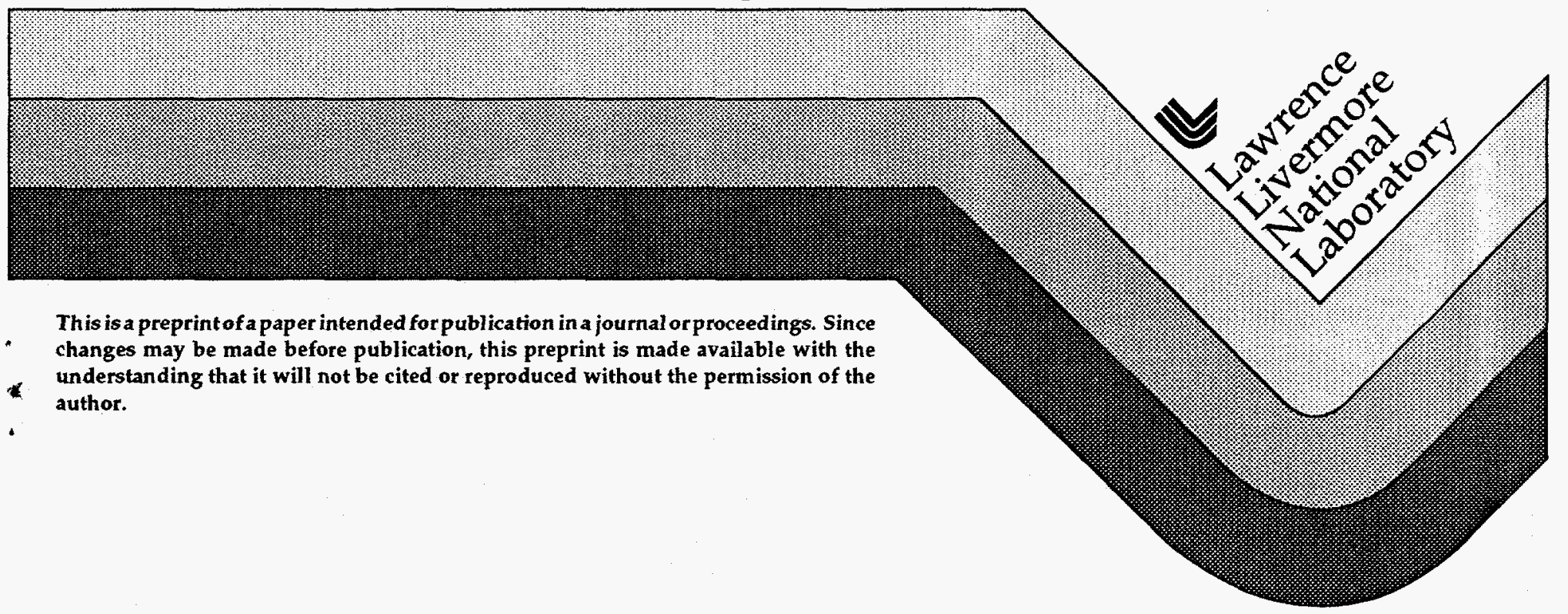




\section{DISCLAIMER}

This document was prepared as an account of work sponsored by an agency of the United States Government. Neither the United States Government nor the University of California nor any of their employees, makes any warranty, express or implied, or assumes any legal liability or responsibility for the accuracy, completeness, or usefulness of any information, apparatus, product, or process disclosed, or represents that its use would not infringe privately owned rights. Reference herein to any specific commercial product, process, or service by trade name, trademark, manufacturer, or otherwise, does not necessarily constitute or imply its endorsement, recommendation, or favoring by the United States Government or the University of California. The views and opinions of authors expressed herein do not necessarily state or reflect those of the United States Government or the University of California, and shall not be used for advertising or product endorsement purposes. 


\section{DISCLAIMER}

Portions of this document may be illegible in electronic image products. Images are produced from the best available original document. 
J.N. GLOSLI ${ }^{*}$.M.R. PHILPOTT ${ }^{* *}$. and J. BELAK ${ }^{*}$

"University of California. Lawrence Livermore National Laboratory. Livermore, CA 94550)

* IBM Research Division. Almaden Research Center, 650) Harry Road. San Jose, CA 95120)-6(199

\begin{abstract}
Amorphous carbon films approximately $20 \mathrm{~nm}$ thick are used throughout the computer industry as protective coatings on magnetic storage disks. The structure and function of this family of materials at the atomic level is poorly understood. Recently, we simulated the growth of $\mathrm{a}: \mathrm{C}$ and a:CH films 1 to $5 \mathrm{~nm}$ thick using Brenner's bond-order potential model with added torsional energy terms. The microstructure shows a propensity towards graphitic structures at low deposition energy (<leV) and towards higher density and diamond-like structures at higher deposition energy $(>20 \mathrm{eV})$. In this paper we present simulations of the evolution of this microstructure for the dense $20 \mathrm{eV}$ films during a simulated indentation by a hard diamond tip. We also simulate sliding the tip across the surface to study dynamical processes like friction, energy transport and microstructure evolution during sliding.
\end{abstract}
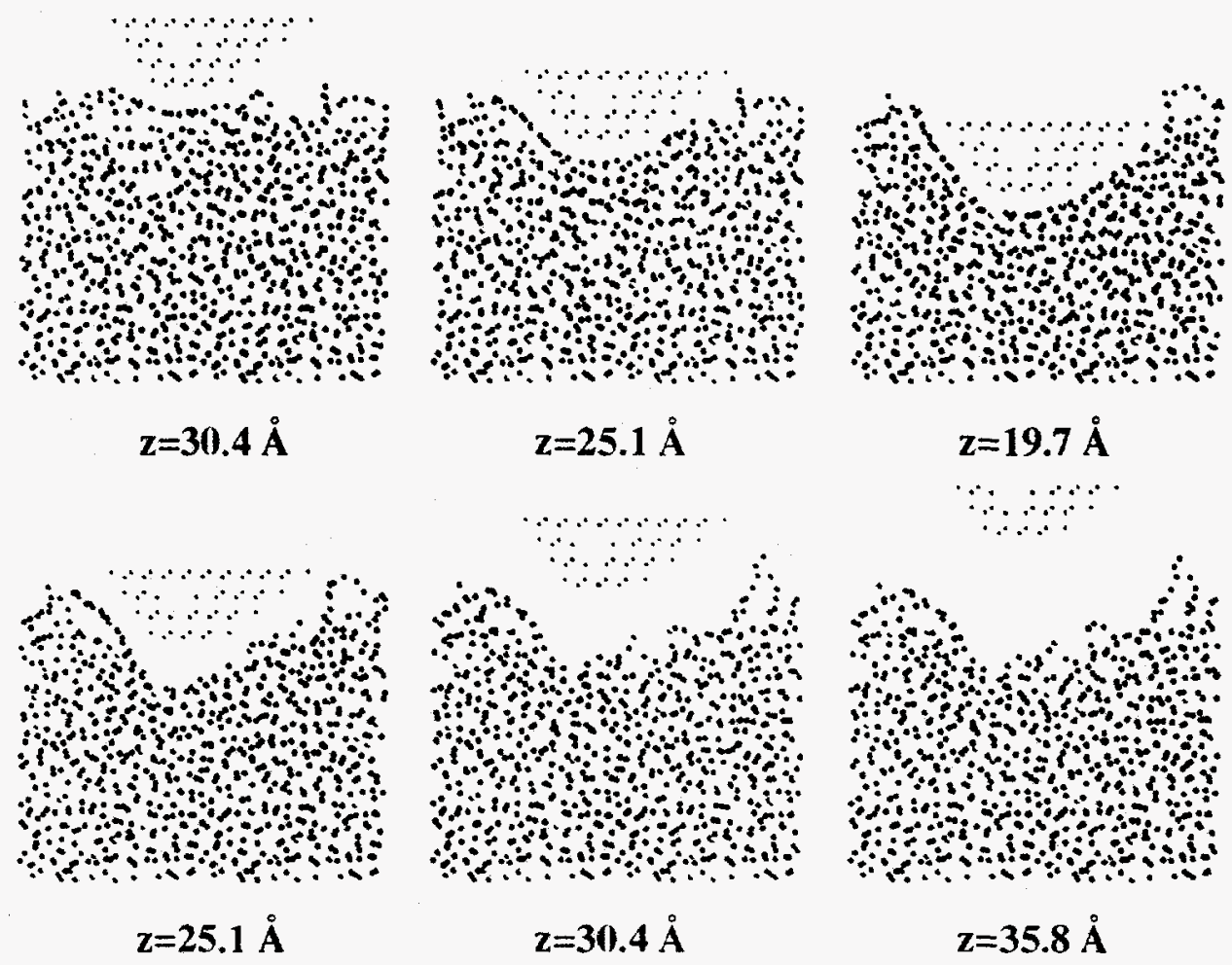

$$
z=19.7 \AA
$$$$
\because \because \because \because
$$

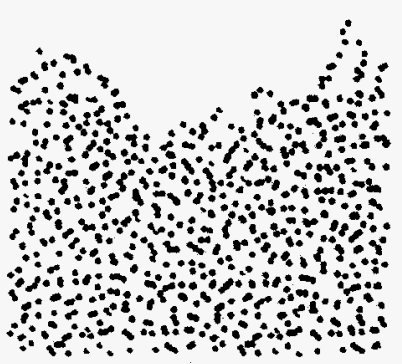

$$
\mathrm{z}=30.4 \AA
$$

$\mathrm{z}=35.8 \AA$

Figure 1. Six snapshots during a MD simulation of indentation and removal of a nondeformable diamond tip into an amorphous carbon substrate. The simulation cell is $4 \mathrm{~nm}$ wide and the snapshots are $1 \mathrm{~nm}$ thick cross-sections through the center of the tool. The indentation rate is $35 \mathrm{~m} / \mathrm{s}$. 


\section{INTRODUCTION}

Amorphous carbon films approximately $20 \mathrm{~nm}$ thick are used throughout the computer industry as protective coatings on magnetic storage disks [1.2]. These films contain significant $\mathrm{sp}^{3}$ fractions and, for this reason. are mechanically hard. have low friction. and are chemically inert. Despite intense experimental [3-9] and theoretical $[11-25]$ interest. the structure and function of these films at the atomic level is poorly understood.

Recently [26] we presented molecular dynamics (MD) simulations of the formation (both quench and deposition) of amorphous carbon films using Brenner's $[27,28]$ empirical bond-order potential. This empirical model, based on ideas of Tersoff [29], mimics the quantum mechanics allowing carbon to form strong chemical bonds with a variety of hybridizations. We find unphysical bonding between three-fold carbon atoms without inclusion of a torsional energy barrier [28]. This model has been extensively used by Harrison [30-34] to study the tribological properties of diamond surfaces.

Our results for the bonding character of the amorphous films is in qualitative agreement with the quantum mechanics based MD studies [15-22]. Three-fold carbon atoms tend to form pairs. We find a peak density as a function of incident carbon energy in the range $20-40 \mathrm{eV}$. slightly less than the previous study using Tersoff's bond-order model [14]. The difference is probably due to our use of the torsional energy.

Here we present results from MD simulations of nano-indentation and sliding on these films.

\section{METHODS}

To create a larger surface simulation cell, we doubled the cell size in $X$ and $Y$ from our previous simulation [26] to about $4 \mathrm{~nm}$ and continued to grow a dense film at $20 \mathrm{eV}$. We stopped the deposition when the film was $4 \mathrm{~nm}$ thick. The tribological boundary conditions are the same as in our previous simulations of metal and ceramics [35]. The bottom-most layer of atoms are fixed. the next few layers are maintained at room temperature. and periodic boundaries are applied in the surface plane. The tip is cleaved from a diamond lattice and blunted to create a radius of about $\mathrm{Inm}$. The tip atoms are held rigid during indentation and sliding and interact with the surface atoms through a truncated Lennard-Jones potential. Indentation was performed at $35 \mathrm{~m} / \mathrm{s}$ and sliding at 35 and $350 \mathrm{~m} / \mathrm{s}$. These rates are comparable to the sliding speeds at the head-disk interface in magnetic recording disks. 

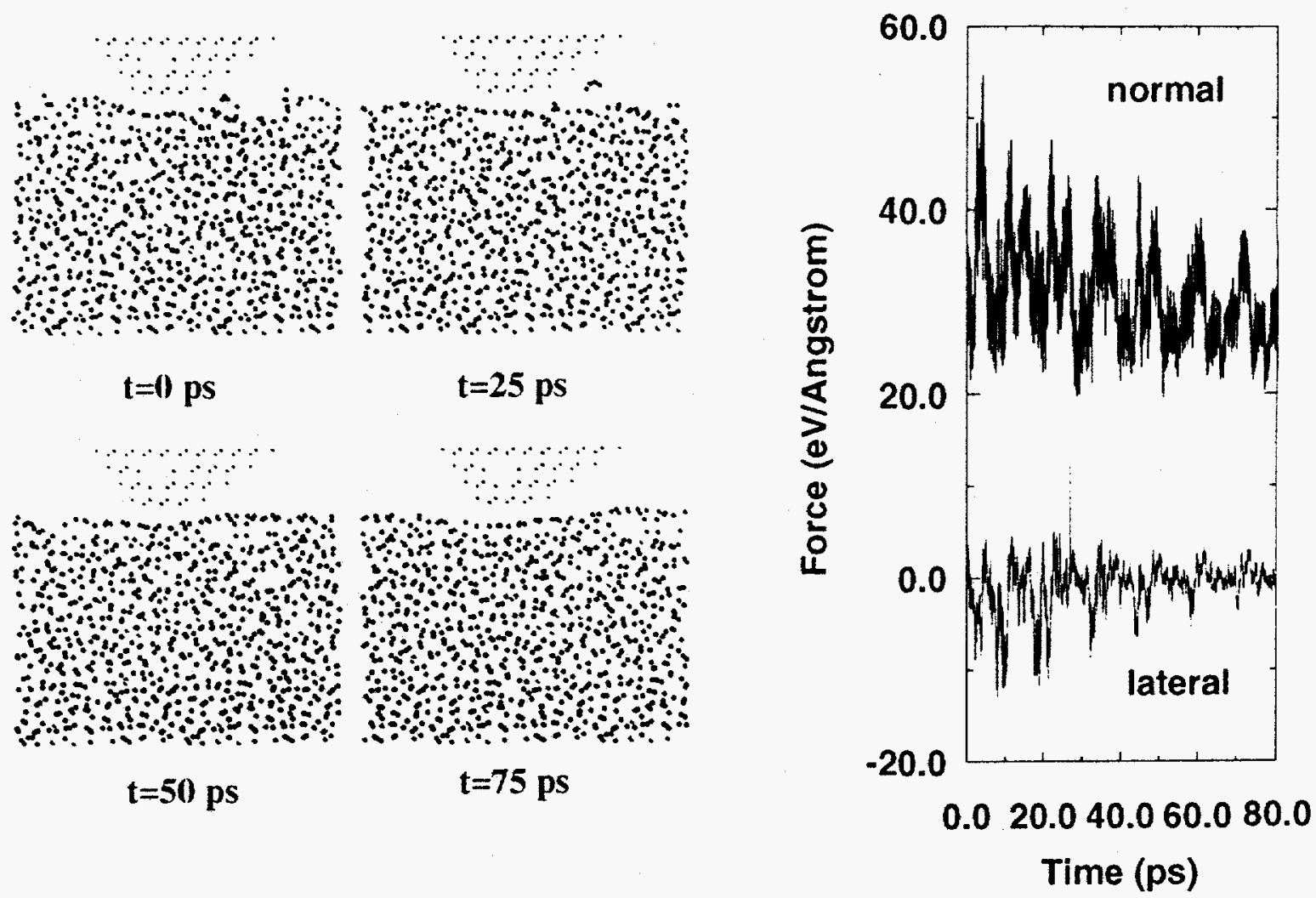

Figure 3. Four snapshots during sliding in contact under a light load. The material is moving from left to right in the figures.

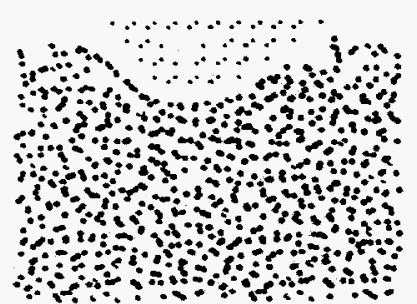

$\mathbf{t}=\mathbf{0}$ ps

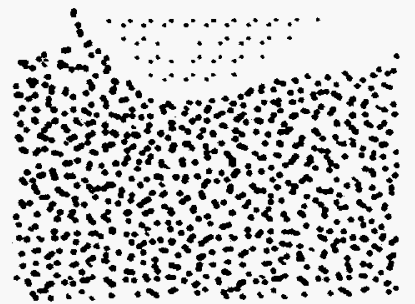

$\mathbf{t}=\mathbf{5 0} \mathrm{ps}$

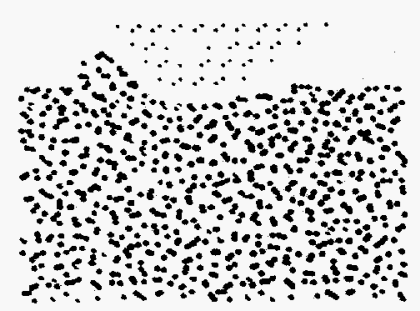

$\mathrm{t}=100 \mathrm{ps}$

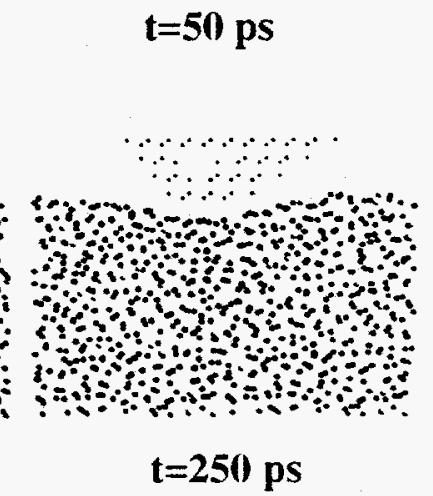

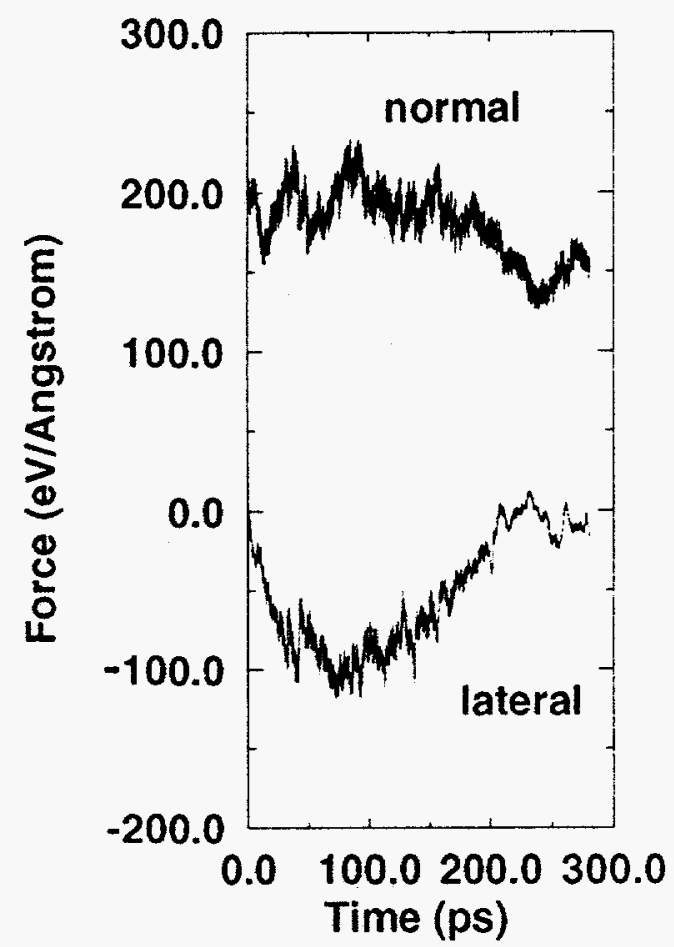

Figure 4. Four snapshots during sliding in contact under a heavy load. The material under the lip densifies leading to a final structure very similar to the starting undeformed structure. 


\section{RESULTS and DISCUSSION}

Six snapshots during loading and unloading are shown in Figure 1. These snapshots are $1 \mathrm{~nm}$ thick cross-sections through the center of the tool. Appreciable plastic deformation occurs and the first layer of surface atoms appear to align with the tool. The loading curve (force on the tool as a function of tool height) is shown in Figure 2. The steps in the curve indicate the onset of plasticity. The curve is reversible before the first step while a hysteresis loop is seen beyond the lirst step. This step-like structure is probably characteristic of covalently bonded materials and represents plastic flow through a rapid rearrangement of the bonding network. The length=scale of our simulations is too small to observe the formation of cracks. The hardness calculated from this simulation is $7525 \mathrm{GPa}$. with the enor arising from our estimate of the contact area. This value agrees well with measured hardness on dense amorphous carbon films [1.2].

Sliding results are shown in Figures 3 and 4 . In both figures the tool is stationary, material moves from left to right and we use periodic boundaries. In Figure 3 we apply a small normal load, less than the first plastic yield seen in Figure 2 . Sliding occurs at $350 \mathrm{~m} / \mathrm{s}$. The tip conditions the surface. That is, dangling atoms are forced into the surface and the top-most layer of carbon atoms are mostly converted to $\mathrm{sp}^{2}$ hybridization. In Figure 4 we apply a normal load greater than the first plastic yield and slide at $35 \mathrm{~m} / \mathrm{s}$. The system initially forms a chip. This chip is compressed into the surface and the density of the film increases. The resulting structure is qualitatively very similar to the initial undeformed structure.

\section{ACKNOWLEDGEMENTS}

Work performed in part under the auspices of the U.S. Department of Energy by the Lawrence Livermore National Laboratory under contract No. W-7405-ENG-48.

\section{REFERENCES}

1. H-C Tsai and D.B. Bogy. J. Vac. Sci. Technol. A 5. 3287 (1987).

2. A. Gill, Wear 168, 143 (1993).

3. F. Li and J.S. Lannin, Phys. Rev. Lett. 65, 1905 (1990).

4. D.R. McKenzie. D. Muller, and B.A. Pailthorpe, Phys. Rev. Lett. 67. 773 (1991).

5. D.R. McKenzie, Y. Yin, N.A. Marks, C.A. Davis, B.A. Pailthorpe. G.A.J. Amaratunga. V.S. Veerasamy, Diamond and Related Materials 3, 353 (1994).

6. K.W.R. Gilkes, P.H. Gaskell, and J. Yaun. Diamond and Related Materials 3. 369 (1994).

7. S.M. Holl, R.D. Johnson. V.J. Novotny, J.L. Williams, C.E. Caley, M. Hoinkis. and R.E. Jones. Proceedings MRS Spring 1994 Symposium, Novel Forms of Carbon II. p54-62.

8. J. Wagner, M. Ramsteiner, Ch. Wild. and P. Koidl, Phys. Rev. B 40. 1817 (1989).

9. M. Weiler. R. Kleber. S. Sattel. K. Jung, H. Ehrhardt. G. Jungnickel. S. Deutschmann. U. Stephan, P. Blaudeck, and Th. Frauenheim, Diamond and Related Materials 3. 245 (1994).

10. D. Beeman. J. Silverman. R. Lynds, and M.R. Anderson. Phys. Rev. B 30. 870 (1984).

11. J. Tersofi. Phys. Rev. Lett. 61. 2879 (1988).

12. B.A. Pailthorpe and P. Knight. Proceedings MRS Spring 1991 Symposium E.

13. B.A. Pailthorpe. J. Appl. Phys. 70. 543 (1991).

14. H-P. Kaukonen and R.M. Nieminen. Phys. Rev. Lett 68. 620 (1992).

15. C.Z. Wang. K.M. Ho, and C.T. Chan, Phys. Rev. Lett. 70. 611 (1993).

16. C.Z. Wang and K.M. Ho. Phys. Rev. Lett. 71, 1184 (1993).

17. D.A. Drabold. P.A. Fedders. and P. Strum. Phys. Rev. B 49. 16415 (1994). 
18. P. Blaudeck, Th. Frauenheim, D. Porezag, G. Seifert. and E. Fromm, J. Phys.: Condens. Matter 4. 6389 (1992).

19. Th. Fraucnheim. P. Blaudeck, U. Stephan, and G. Jungnickel, Phys. Rev. B 48, 4823 (1993).

20. Th. Frauenheim. U. Stephan. P. Blaudeck, and G. Jungnickel. Diamond and Related Materials 3. $462(1994)$.

21. G. Jungnickel. M. Kuhn, S. Deutschmann. F. Richter. U. Stephan. P. Blaudeck. and Th. Frauenheim. Diamond and Related Materials 3. 1056 (1994).

22. Th. Frauenheim. G. Jungnickel, Th. Kohler. and U. Stephan. J. Non-Cryst. Solids 182. 186 (1995).

23. J. Rohertson and E.P. O'Reilly. Phys. Rev. B 35. 2946 (1987).

24. J. Robertson, Diamond and Related Materials 2. 984 (1993).

25. J. Robertson, Diamond and Related Materials 3. 361 (1994).

26. J.N. Glosli. J. Belak, and M.R. Philpott. Proceedings MRS Fall 1994 Symposium. Thin Films: Stresses and Mechanical Properties IV.

27.D.W. Brenner, Phys. Rev. B 42, 9458 (1990).

28. D.W. Brenner, J.A. Harrison, C.T. White. and R.J. Colton. Thin Solid Films 206, 220 (1991).

29. J. Tersoff, Phys. Rev. B 37, 6991 (1988).

30. J.A. Harrison, D.W. Brenner, C.T. White, and R.J. Colton, Thin Solid Films 206, 213 (1991).

31 J.A. Harrison, C.T. White, R.J. Colton, and D.W. Brenner, Phys. Rev. B 46. 9700 (1992).

32 J.A. Harrison, C.T. White, R.J. Colton, and D.W. Brenner, Surface Science 271, 57 (1992).

33. J.A. Harrison, C.T. White, R.J. Colton, and D.W. Brenner, J. Phys. Chem 97, 6573 (1993).

34. J.A. Harrison, R.J. Colton, C.T. White, and D.W. Brenner, Wear 168, 127 (1993).

35. J. Belak. D.B. Boercker, and I.F. Stowers, MRS Bulletin 18, 55 (1993). 